\title{
Padrão estomático de Capsicum ssp. resistentes e suscetíveis a Oidiopsis haplophylli ${ }^{1}$
}

\author{
Milton Luiz Paz Lima ${ }^{1}$, Carlos Alberto Lopes ${ }^{2} \&$ Adalberto Corrêa Café Filho ${ }^{1}$
}

${ }^{1}$ Universidade de Brasília, Depto. de Fitopatologia, CEP 70910-900, Brasília-DF;

${ }^{2}$ Embrapa Hortaliças, Caixa Postal 218, CEP 70.359-970, Brasília, DF. Trabalho financiado pelo CNPq. * Parte da dissertação de Mestrado do primeiro autor. Universidade de Brasília (2002), com bolsa de mestrado do CNPq.

Autor para correspondência: Milton Luiz da Paz Lima. (fitolima@gmail.com)

Data de chegada: 17/10/2007. Aceito para publicação em: 08/10/2009.

\section{RESUMO}

Paz Lima, M.L., Lopes, C.A. \& Café Filho, A.C. Padrão estomático de Capsicum spp. resistentes e suscetíveis a Oidiopsis haplophylli. Summa Phytopathologica, v.36, n.1, p.25-29, 2010.

Visando relacionar a reação de Capsicum spp. resistentes e suscetíveis à Oidiopsis haplophylli com o padrão dos respectivos complexos estomáticos, foram analisados em dois ensaios, 5 e 15 genótipos de Capsicum spp. em delineamento inteiramente casualizado. Avaliou-se a abertura do ostíolo, a morfometria do estômato (comprimento, largura e área), o número de estômatos. $\mathrm{mm}^{-2}$ e a freqüência de estômatos (unidades de estômatos por células da epiderme) nas superfícies adaxial e abaxial da epiderme foliar de plantas cultivadas em casa-de-vegetação. A variável abertura ostiolar não explicou a reação dos genótipos ao oídio, nem na face adaxial $\left(R^{2}=0,16\right)$ nem na abaxial $\left(R^{2}=0,13\right)$. Entretanto, o número de estômatos. $\mathrm{mm}^{-2}$ explicou a reação ao oídio em $84 \%$ (face adaxial) ou $74 \%$ (face abaxial). Para a freqüência de estômatos, o modelo ajustou-se melhor na face adaxial $\left(\mathrm{R}^{2}=0,76\right)$, do que na face abaxial $\left(\mathrm{R}^{2}=0,48\right)$. Maiores números e freqüências de estômatos em ambas as faces foliares ocorreram em pimentão 'Magali' (altamente suscetível), com valores significativamente maiores do que em 'HV-12' (altamente resistente). Sugere-se que a suscetibilidade de genótipos de Capsicum a $O$. haplophylli está parcialmente relacionada a mecanismos de defesa estruturais pré-formados, como o número e freqüência de estômatos, os quais se relacionam com o número de sítios de infecção. Por outro lado, para alguns genótipos, esta relação não foi significativa, indicando que outros mecanismos de resistência também estejam envolvidos.

Palavras-chave adicionais: Leveillula taurica, estômato, oídio, pimentão, pimenta, mecanismos de resistência.

\section{ABSTRACT}

Paz Lima, M.L., Lopes, C.A. \& Café Filho, A.C. Stomatal patterns of Capsicum genotypes resistant or susceptible to Oidiopsis haplophylli. Summa Phytopathologica, v.36, n.1, p.25-29, 2010.

This work reports the reaction of Capsicum genotypes to the powdery mildew pathogen with variables of the stomatal complex, from samples of five to 15 Capsicum genotypes in a complete randomized experiments. Ostiolum size, stomatal morphometry (length, width and surface area), the number of stomata. $\mathrm{mm}^{-2}$, and the frequency of stomata (stomatal units per unit of epidermal cells) were evaluated on both leaf epidermal surfaces of plants growing in greenhouse. The variable ostiolum size did not explain the genotype reaction to the mildew, neither in the upper $\left(\mathrm{R}^{2}=0.16\right)$ or lower leaf surfaces $\left(R^{2}=0.13\right)$. Nevertheless, the number of stomata. $\mathrm{mm}^{-2}$, on the upper or lower leaf surfaces, explained $84 \%$ to $74 \%$ of the genotype reaction, respectively. For the relation between stomatal frequency and host reaction, a better fit was found with the number of stoma in the upper leaf surface $\left(\mathrm{R}^{2}=0.76\right)$, than with number in the lower leaf surface $\left(\mathrm{R}^{2}=0.48\right)$. Sweet pepper 'Magali' (highly susceptible) had the largest numbers and frequency of stomata on both leaf surfaces at both experiments, which were significantly higher than in ' $\mathrm{HV}-12$ ' (highly resistant). We suggest that the susceptibility of Capsicum to $O$. haplophylli may be partially related to pre-formed structural defense mechanisms, such as number of stomata, which relates to the number of infection sites. However, the low correlation of the disease and variables of the stomatal complex among some genotypes, indicates that other mechanisms might be involved with the expression of resistance in Capsicum to powdery mildew.

Keywords: Leveillula taurica, stoma, resistance groups, hot pepper, chili, sweet pepper.

O oídio causado por Oidiopsis haplophylli (Lev.) Salmon (syn. $O$. taurica) é uma das doenças mais importantes do pimentão (Capsicum annuит L.), principalmente em cultivo protegido, onde pode causar danos significativos (4). A infecção de O. haplophylli ocorre via estômato e o micélio endofítico de desenvolve entre as células do parênquima lacunoso (11). Após a infecção, ocorre a emergência de conidióforos através da abertura ostiolar que possui área aproximada de $90 \mathrm{~mm}^{2}$, suficiente para penetração ativa dos tubos germinativos de fungos. O número de estômatos na maioria das dicotiledôneas é razoavelmente constante dentro da espécie (5). Capsicum annuum apresenta cerca de 200 estômatos. $\mathrm{mm}^{-2}$, a abertura ostiolar é de 22-32 $\mu \mathrm{m}$ de padrão cruciferáceo, anfiestomática, tendo células epidérmicas de formato sinuoso em ambas as faces foliares (2)

Além de sua importância fisiológica, os estômatos são claramente de grande importância como via de penetração de vários agentes fitopatogênicos (5). Em geral, há maior densidade estomática na face abaxial, o que reduz a perda de água das folhas. Assim, o fato de as plantas de Capsicum apresentarem maior número e freqüência de 
estômatos na face abaxial (5) indica que esta face como o principal sítio de infecção ao oídio.

Este estudo visou relacionar as características morfológicas de estômatos (número, frequência, tamanho do ostíolo, comprimento, largura e relação $\mathrm{C} / \mathrm{L}$ ) de folhas de pimentas e pimentões com grupos de resistência ao oídio previamente identificados $(10 ; 12 ; 17)$.

\section{MATERIAIS E MÉTODOS}

Foram conduzidos dois experimentos onde foram utilizadas plantas cultivadas em canteiros de casa-de-vegetação da Estação Experimental de Biologia, da Universidade de Brasília, DF. Foram analisados, em delineamento inteiramente casualizado, cinco genótipos de $C$. annuum e 15 genótipos de Capsicum spp (13 de C. annuum, um de $C$. baccatum e um de $C$. chinense), representantes de grupos de resistência a $O$. haplophylli analisados em oito repetições, cada planta representando uma repetição. Os genótipos representaram as seguintes classes de resistência: altamente resistente (AR), resistente (R), moderadamente resistente (MR), moderadamente suscetível (MS) e altamente suscetível (AS).

A semeadura foi realizada em oito vasos (2L, de alumínio, solo esterilizado) por genótipo (no estádio de 7-12 folhas) inoculados com $O$. haplophylli na concentração de $10^{4}$ conídios.ml-1 ${ }^{-1}$ Aos 56 dias após a inoculação foram coletadas aleatoriamente três folhas de quatro plantas infectadas de cada genótipo, no período da manhã. Em seguida, fez-se a impressão da epiderme em lâminas de vidro contendo cola plástica (9), nas duas faces foliares. Em intervalos diários (total de 27 avaliações), estimou-se a incidência (In-\%), índice de esporulação (Ide-notas), índice de incidência (Idn-notas) e severidade (Is-notas), variáveis e escalas descritas por Paz Lima et al. (12).

Foi estimada a curva de evolução temporal e a área abaixo da curva de progresso da doença (AACPD), sendo estas submetidas à análise multivariada (análise de agrupamentos, medida de similaridade UPGMA), para separação dos genótipos em grupos de resistência, utilizando o programa SAS "for windows".

Foram avaliados os tamanhos do ostíolo (comprimento transversal da abertura, $\mathrm{mm}$ ), morfometria do estômato [comprimento $\mathrm{C}$, largura $\mathrm{L}(\mathrm{mm})$ e área $\left(\mathrm{C} * \mathrm{~L}, \mathrm{~mm}^{2}\right)$ ], número de estômatos. $\mathrm{mm}^{-2} \mathrm{e}$ a freqüência de estômatos (unidade de estômatos / unidade de células da epiderme) na epiderme foliar (faces adaxial e abaxial). O número de estômatos e a frequiência de estômatos foram determinados em microscópio composto de câmara clara $(160 \mathrm{X})$, numa área de impressão foliar de $1 \mathrm{~mm}^{2}$. A freqüência estomatal é uma variável descrita por Cutter (5) que mede a quantidade de estômatos pelo número de células epidérmicas na área considerada.

O estudo de correlação das estruturas anatômicas com as classes de resistência foi efetuado em dois experimentos. Inicialmente, foram analisados cinco genótipos [ 'HV-12' (AR), 'Shishito' (R), 'Reinger' (MR), 'Magnata' (MS), 'Magali' (AS)], avaliando-se o número de estômatos. $\mathrm{mm}^{-2}$, freqüência estomatal (\%) e abertura ostiolar $(\mathrm{mm})$, tomando 16 observações para a variável abertura ostiolar $(\mathrm{mm})$ nas faces abaxial e adaxial. Posteriormente, avaliouse em 15 genótipos o número de estômatos. $\mathrm{mm}^{-2}$, a freqüência estomatal (\%) e a morfometria estomatal tomando-se 20 observações por tratamento ao acaso e por folha. As análises de variâncias, testes de separação de médias (Tukey), desdobramentos e contrastes ortogonais foram realizados os programas SAS e Genes.

\section{RESULTADOS E DISCUSSÃO}

Através da análise de agrupamento três genótipos ('Elisa', 'Magali' e 'PI 193469') foram classificados como altamente suscetíveis (AS), três ('Magnata', 'Hercules 672' e 'Margarita') como moderadamente suscetíveis (MS), cinco ('PI 201234', '306-CM320', 'Pimenta olho de ganso', 'Reinger' e 'Alongado') foram classificados como moderadamente resistentes (MR), três ('Shishito', 'PI 182925' e 'PI 322719') foram classificados como resistentes (R) e apenas o genótipo 'HV-12' foi classificado como altamente resistente ao oídio, não sendo observado o desenvolvimento de sintomas em suas folhas (Tabela 1).

Tabela 1. Valores de AACPD da incidência da doença (In-\%), índice de esporulação (Ide-notas), índice de incidência (Idn-notas) e severidade (Isnotas) para 15 genótipos de Capsicum infectados por Oidiopsis haplophylli*.

\begin{tabular}{lllrrrr}
\hline Genótipos & $\begin{array}{c}\text { Grupo de } \\
\text { Resistência }\end{array}$ & In-\% & Ide-notas & Idn-notas & Is-notas \\
\hline HV-12 & 1 & AR & 0,0 & 0,0 & 0,0 & 0,0 \\
Shishito & 2 & R & 1235,5 & 76,0 & 106,0 & 179,2 \\
PI 182925 & 2 & R & 2232,2 & 113,6 & 108,0 & 212,0 \\
PI 322719 & 2 & R & 72,2 & 12,1 & 14,7 & 272,2 \\
Alongado & 2 & MR & 1166,2 & 67,2 & 166,2 & 179,0 \\
PI 201234 & 3 & MR & 3792,5 & 163,5 & 88,4 & 324,9 \\
306-CM320 & 3 & MR & 1542,0 & 89,2 & 94,8 & 170,6 \\
Pimenta Olho & & & & & & \\
de Ganso & 3 & MR & 1850,2 & 79,8 & 119,6 & 166,2 \\
Reinger & 3 & MR & 3862,7 & 159,6 & 174,2 & 327,2 \\
Hercules 672 & 4 & MS & 4363,0 & 157,0 & 169,0 & 345,2 \\
Margarita & 4 & MS & 3985,2 & 174,1 & 187,1 & 342,9 \\
Magnata & 5 & MS & 3804,8 & 157,1 & 187,8 & 332,9 \\
Elisa & 5 & AS & 4192,6 & 165,8 & 176,2 & 336,7 \\
Magali & 5 & AS & 4448,4 & 176,4 & 184,0 & 357,0 \\
PI 193469 & 5 & AS & 4143,9 & 184,3 & 173,4 & 362,9 \\
\hline
\end{tabular}

*I - Altamente resistente, R - resistente, MR - moderadamente resistente, MS moderadamente suscetível, AS - altamente suscetível; In-\%, Incidência; Ide-notas, índice de esporulação; Idn-notas, Índice de incidência e Is-notas severidade.

Houve variação no número de estômatos nas duas faces foliares, com médias de $58 \pm 29,2$ e $194 \pm 55,8$ estômatos. $\mathrm{mm}^{-2}$, nas faces adaxial e abaxial respectivamente (Tabela 2). Os valores médios encontrados na face abaxial foram semelhantes ao valor de 200 estômatos. $\mathrm{mm}^{-2}$ encontrado na descrição original de folhas de Capsicum spp. (2). Em todos os 15 genótipos avaliados houve maior número e frequiência de estômatos na face abaxial diferindo estatisticamente da face adaxial (Tabela 3), sendo este um sítio de infecção de O. haplophylli, e um alvo importante nas medidas de controle. A forma das células epidérmicas de todos os genótipos analisados foi sinuosa e os tipos de estômatos encontrados nos cinco genótipos de Capsicum foram anisocíticos predominantemente, sendo encontrado também o padrão anomocítico (2).

Os valores dos coeficientes de determinação $\left(R^{2}\right)$, entre os efeitos do número e da frequência de estômatos e a reação dos genótipos mostram sob forma percentual o quanto estas variáveis explicam a variação existente entre os genótipos avaliados. Na face adaxial, o número de estômatos explica a variação entre os genótipos em 84 \%; 
Tabela 2. Número de estômatos.mm ${ }^{-2}$, frequiência estomatal (\%) e abertura ostiolar (mm), em ambas as faces foliares em Capsicum annuum representantes de cinco grupos de resistência à Oidiopsis haplophylli.

\begin{tabular}{|c|c|c|c|c|c|c|c|}
\hline \multirow[t]{2}{*}{ Genótipos } & \multirow[t]{2}{*}{ GR* } & \multicolumn{2}{|c|}{$\mathrm{N}^{0}$ estômatos.mm ${ }^{-2}$} & \multicolumn{2}{|c|}{ Freqüência estomatal (\%) } & \multicolumn{2}{|c|}{ Abertura ostiolar (mm) } \\
\hline & & Adaxial & Abaxial & Adaxial & Abaxial & Adaxial & Abaxial \\
\hline HV12 & AR & $38,8 \mathrm{c}^{* *}$ & $164,8 \mathrm{~cd}^{* *}$ & $7,0 \mathrm{~b}^{* *}$ & $24,2 \mathrm{~b}^{* *}$ & $10,3 \mathrm{bc}^{* *}$ & $10,8 \mathrm{a}^{* *}$ \\
\hline Shishito & $\mathrm{R}$ & $36,6 \mathrm{c}$ & $140,2 \mathrm{~d}$ & $10,2 \mathrm{a}$ & $23,4 \mathrm{~b}$ & $12,0 \mathrm{a}$ & $12,0 \mathrm{a}$ \\
\hline Reinger & MR & $42,2 \mathrm{c}$ & $174,4 \mathrm{bc}$ & $7,5 \mathrm{~b}$ & $27,9 \mathrm{a}$ & $8,9 \mathrm{c}$ & $11,0 \mathrm{a}$ \\
\hline Magnata & MS & $71,6 b$ & $206,8 \mathrm{~b}$ & $12,1 \mathrm{a}$ & $24,3 b$ & $10,0 \mathrm{bc}$ & $10,9 \mathrm{a}$ \\
\hline Magali & AS & 104,4 a & 284,4 a & $12,8 \mathrm{a}$ & $30,6 \mathrm{a}$ & $11,6 \mathrm{a}$ & $12,0 \mathrm{a}$ \\
\hline Média & & 58,72 & 194,12 & 9,92 & 26,8 & 10,56 & 11,34 \\
\hline
\end{tabular}

* Grupo de resistência (GR); AR - Altamente Resistente ou Imune, R - resistente, MR - moderadamente resistente, MS - moderadamente suscetível, AS - altamente suscetível.

*** Valores seguidos de mesma letra na vertical, não diferem entre si pelo teste Tukey ( $\mathrm{P} \leq 0,05)$

já na face abaxial, a variação é explicada em $74 \%$. Deste modo, o genótipo que apresentou maior número de estômatos. $\mathrm{mm}^{-2}$ na superfície abaxial foi 'Magali' (Tabela 2), previamente classificado como altamente suscetível $(12,17)$. A freqüência de estômatos foi também maior em plantas suscetíveis do que em plantas resistentes, tanto na face adaxial $\left(R^{2}=0,76\right)$ quanto na face abaxial $\left(R^{2}=0,48\right)$. Por outro lado, o tamanho da abertura ostiolar $(\mu \mathrm{m})$ explicou em apenas $16 \%$ na face adaxial e $13 \%$ na face abaxial a reação dos genótipos ao oídio, percentuais muito baixos descartando o relacionamento das variáveis morfométricas $(\mathrm{C}, \mathrm{L}$ e C*L) com a resistência de Capsicum à doença. A variável abertura ostiolar também não explicou adequadamente a reação dos genótipos nas faces adaxial $\left(R^{2}=0,16\right)$ ou abaxial $\left(R^{2}=\right.$ $0,13)$.

A face abaxial apresentou maior número e frequiência de estômatos, e explicou $74 \%$ da reação dos genótipos ao oídio (Tabela 4). Isso sugere que esta variável é importante determinante da resistência de Capsicum ao oídio.

Esperava-se maior número e frequiência de estômatos na face abaxial dos genótipos AS, fato confirmado para 'Magali' (Tabelas 2 e 3 ) mas não para 'Elisa', que apresentou-se estatisticamente semelhante ao genótipo HV-12 (AR) (Tabela 3). Em conjunto, isto sugere que a resistência pode estar associada a fatores pré-formados do hospedeiro para determinados genótipos, mas que outros fatores também estão envolvidos na determinação da resistência neste patossistema.

Na face adaxial, os genótipos 'Magali' (AS) e 'PI 201234' (MR) apresentaram os maiores números de estômatos. Na face abaxial, destacaram-se os genótipos 'Pimenta Olho de Ganso' (MR) e 'Magali' (AS). No caso da freqüência de estômatos, o genótipo 'Alongado' (MR) e 'Pimenta Olho de Ganso' (MR) na face abaxial e os genótipos 'Magnata' (MS) e 'Magali' (AS) na face adaxial apresentaram as maiores freqüências. Assim, para alguns genótipos, para ambas as faces foliares, os maiores números e freqüências de estômatos encontraram-se distribuídos em genótipos com comportamento MR, MS e AS (Tabela 3). Em outros estudos realizados nos patossistemas café-Hemileia vastatrix (1), mandioca-Xanthomonas campestris (6), cacau-Phytophthora palmivora (8) e mostarda-Alternaria brassicae (16), o relacionamento da resistência com aspectos morfológicos não foi observado.

Tabela 3. Número e frequiência de estômatos em genótipos de Capsicum representantes de cinco grupos de resistência à Oidiopsis haplophylli.

\begin{tabular}{|c|c|c|c|c|c|c|}
\hline \multirow[t]{2}{*}{ Genótipo ** } & \multicolumn{3}{|c|}{ Número de estômatos* } & \multicolumn{3}{|c|}{ Freqüência de estômatos* } \\
\hline & Face Adaxial & Face Abaxial & Média das Faces & Face Adaxial & Face Abaxial & Média das Faces \\
\hline HV-12 (AR) & 38,8 de $B$ & $164,8 \mathrm{fg} \mathrm{A}$ & $101,8 \mathrm{fg}$ & 7,0 e $\mathrm{B}$ & 24,2 hi A & $15,6 \mathrm{~h}$ \\
\hline Shishito (R) & 36,6 de $B$ & $140,2 \mathrm{~g} \mathrm{~A}$ & $88,4 \mathrm{~g}$ & 10,2 de $B$ & 23,4 i A & $16,8 \mathrm{gh}$ \\
\hline PI 182925 (R) & 28,6 e B & $144,8 \mathrm{~g} \mathrm{~A}$ & $86,7 \mathrm{~g}$ & 6,9 e B & 27,2 hi $\mathrm{A}$ & $17,0 \mathrm{gh}$ \\
\hline PI 322719 (R) & 43,4 de $B$ & 216,2 de $A$ & $129,8 \mathrm{ef}$ & 8,7 de $\mathrm{B}$ & $32,0 \mathrm{bc} \mathrm{A}$ & $20,3 \mathrm{fg}$ \\
\hline PI 201234 (MR) & $92,8 \mathrm{ab} \mathrm{B}$ & 245,4 b A & $169,1 \mathrm{bc}$ & 13,7 b B & 29,7 fg A & $21,7 \mathrm{~cd}$ \\
\hline 306-CM320 (MR) & 55,4 de $B$ & 199,4 ef $A$ & 127,4 ef & 9,7 de $\mathrm{B}$ & $27,9 \mathrm{gh} \mathrm{A}$ & $18,8 \mathrm{gh}$ \\
\hline Pim Olho de Ganso (MR) & 39,0 de $B$ & 317,0 a A & $178,0 \mathrm{ab}$ & 7,5 de $B$ & $33,9 \mathrm{ab} A$ & 20,7 ef \\
\hline Alongado (MR) & $70,2 \mathrm{~cd} \mathrm{~B}$ & 240,0 bc A & $155,1 \mathrm{~cd}$ & $12,0 \mathrm{bc} B$ & 34,8 a A & $23,4 \mathrm{bc}$ \\
\hline Margarita (MS) & 58,2 de $B$ & 198,0 ef $\mathrm{A}$ & 128,1 ef & 10,1 de $B$ & $27,6 \mathrm{gh} \mathrm{A}$ & $18,9 \mathrm{gh}$ \\
\hline Reinger (MR) & $64,4 \mathrm{~cd} \mathrm{~B}$ & 203,4 de A & 133,9 ef & $11,1 \mathrm{~cd} \mathrm{~B}$ & 28,4 fg A & $19,8 \mathrm{fg}$ \\
\hline Hercules 672 (MS) & $64,8 \mathrm{~cd} \mathrm{~B}$ & $237,4 \mathrm{~cd} \mathrm{~A}$ & $151,1 \mathrm{~cd}$ & $11,1 \mathrm{~cd} \mathrm{~B}$ & $31,5 \mathrm{~cd} A$ & $21,3 \mathrm{~cd}$ \\
\hline PI 193469 (AS) & $64,2 \mathrm{~cd} \mathrm{~B}$ & $237,2 \mathrm{~cd} \mathrm{~A}$ & $150,7 \mathrm{de}$ & $11,1 \mathrm{cdB}$ & 31,3 de $A$ & $21,2 \mathrm{de}$ \\
\hline Magnata (MS) & 71,6 bc B & 206,8 de $\mathrm{A}$ & $139,2 \mathrm{de}$ & 27,8 a $\mathrm{A}$ & 24,3 hi B & $26,0 \mathrm{ab}$ \\
\hline Magali (AS) & 104,4 a B & 284,4 a A & $194,4 \mathrm{a}$ & 24,3 a B & 30,6 ef $\mathrm{A}$ & $27,4 \mathrm{a}$ \\
\hline Elisa (AS) & 45,4 de B & 187,2 ef $A$ & $116,3 \mathrm{fg}$ & 8,0 de $B$ & 26,6 hi A & $17,3 \mathrm{gh}$ \\
\hline Médias & $58,5 \mathrm{~B}$ & $214,8 \mathrm{~A}$ & & $28,9 \mathrm{~A}$ & $11,9 \mathrm{~B}$ & \\
\hline
\end{tabular}

*Valores seguidos de mesma letra em maiúscula e na horizontal não diferem entre si ao Teste Tukey (P 0,05); Valores seguidos de mesma letra em minúscula e na vertical não diferem entre si ao Teste Tukey $(\mathrm{P} \sim 0,05)$

** AR-altamente resistente, R-resistente, MR-moderadamente resistente, MS-moderadamente suscetível, AS-altamente suscetível. Genótipos em negrito correspondem aos genótipos avaliados inicialmente (testemunhas) 
Tabela 4. Morfometria estomatal (comprimento, largura, dimensão estomatal - C*L) nas faces adaxial e abaxial de 15 genótipos de Capsicum infectados por Oidiopsis haplophylli.

\begin{tabular}{|c|c|c|c|c|c|c|}
\hline \multirow{2}{*}{ Genótipos** } & \multicolumn{3}{|c|}{ Face adaxial $(\mu \mathrm{m}) *$} & \multicolumn{3}{|c|}{ Face abaxial $(\mu \mathrm{m}) *$} \\
\hline & $\begin{array}{c}\text { Comprimento } \\
(\mathrm{C}-\mu \mathrm{m})\end{array}$ & $\begin{array}{c}\text { Largura } \\
(\mathrm{L}-\mu \mathrm{m})\end{array}$ & $\begin{array}{l}\mathbf{C} * \mathbf{L} \\
\left(\mu \mathbf{m}^{2}\right)\end{array}$ & $\begin{array}{l}\text { Comprimento } \\
(\mathrm{C}-\mu \mathrm{m})\end{array}$ & $\begin{array}{c}\text { Largura } \\
(\mathrm{L}-\mu \mathrm{m})\end{array}$ & $\begin{array}{l}\mathbf{C} * \mathbf{L} \\
\left(\mu \mathbf{m}^{2}\right)\end{array}$ \\
\hline HV-12 (AR) & $33,3 \mathrm{bc}^{8}$ & $18,7 \mathrm{~cd}^{14}$ & $634,3 \mathrm{de}^{11}$ & $34,5 \mathrm{bc}^{7}$ & $23,5 \mathrm{bc}^{9}$ & $814,5 \mathrm{bc}^{6}$ \\
\hline Shishito (R) & $37,7 \mathrm{a}^{1}$ & $26,3 \mathrm{a}^{1}$ & $1001,4 \mathrm{a}^{1}$ & $38,8 \mathrm{a}^{1}$ & $27,8 \mathrm{a}^{1}$ & $1080,0 \mathrm{a}^{1}$ \\
\hline PI 182925 (R) & $35,4 \mathrm{ab}^{5}$ & $21,7 \mathrm{bc}^{3}$ & $766,6 \mathrm{~cd}^{4}$ & $32,1 \mathrm{bc}^{14}$ & $23,9 \mathrm{bc}^{8}$ & $778,7 \mathrm{bc}^{12}$ \\
\hline PI 322719 (R) & $33,4 \mathrm{bc}^{10}$ & $18,0 \mathrm{~d}^{15}$ & $602,2 \mathrm{de}^{14}$ & $32,2 \mathrm{bc}^{13}$ & $23,1 \mathrm{bc}^{11}$ & $768,1 \mathrm{bc}^{14}$ \\
\hline PI 201234 (MR) & $32,9 \mathrm{bc}^{13}$ & $18,9 \mathrm{~cd}^{13}$ & $628,9 \mathrm{de}^{12}$ & $34,7 \mathrm{bc}^{5}$ & $22,4 \mathrm{c}^{14}$ & $788,2 \mathrm{bc}^{10}$ \\
\hline 306-CM320 (MR) & $33,4 \mathrm{bc}^{9}$ & $19,3 \mathrm{~cd}^{11}$ & $643,3 \mathrm{de}^{10}$ & $34,0 \mathrm{bc}^{8}$ & $23,0 \mathrm{bc}^{12}$ & $788,7 \mathrm{bc}^{9}$ \\
\hline Pim. Olho de Ganso (MR) & $30,5 \mathrm{c}^{14}$ & $19,1 \mathrm{~cd}^{12}$ & $722,7 \mathrm{de}^{7}$ & $30,6 c^{15}$ & $22,2 \mathrm{c}^{15}$ & $681,5 c^{15}$ \\
\hline Alongado (MR) & $35,3 \mathrm{ab}^{6}$ & $20,8 \mathrm{~cd}^{5}$ & $738,8 \mathrm{de}^{5}$ & $34,8 \mathrm{bc}^{4}$ & $24,9 \mathrm{bc}^{3}$ & $876,9 \mathrm{bc}^{3}$ \\
\hline Reinger (MR) & $35,9 \mathrm{ab}^{3}$ & $20,2 \mathrm{~cd}^{8}$ & $728,0 \mathrm{de}^{6}$ & $35,6 \mathrm{ab}^{2}$ & $24,4 \mathrm{bc}^{4}$ & $869,7 \mathrm{bc}^{4}$ \\
\hline Margarita (MS) & $35,6 \mathrm{ab}^{4}$ & $22,6 \mathrm{~b}^{2}$ & $803,1 b^{2}$ & $35,0 \mathrm{bc}^{3}$ & $26,5 \mathrm{ab}^{2}$ & $941,5 \mathrm{ab}^{2}$ \\
\hline Magnata (MS) & $33,0 \mathrm{bc}^{12}$ & $20,3 \mathrm{~cd}^{7}$ & $672,1 \mathrm{de}^{8}$ & $32,4 \mathrm{bc}^{12}$ & $24,0 \mathrm{bc}^{6}$ & $785,1 \mathrm{bc}^{11}$ \\
\hline Hercules 672 (MS) & $33,0 \mathrm{bc}^{11}$ & $20,1 \mathrm{~cd}^{9}$ & $666,4 \mathrm{de}^{9}$ & $33,2 \mathrm{bc}^{11}$ & $22,9 \mathrm{bc}^{13}$ & $772,2 \mathrm{bc}^{13}$ \\
\hline PI 193469 (AS) & $29,9 c^{15}$ & $19,8 \mathrm{~cd}^{10}$ & $604,2 \mathrm{de}^{13}$ & $33,4 \mathrm{bc}^{9}$ & $23,4 \mathrm{bc}^{10}$ & $793,1 \mathrm{bc}^{8}$ \\
\hline Magali (AS) & $36,6 \mathrm{ab}^{2}$ & $21,7 \mathrm{bc}^{4}$ & $801,1 \mathrm{bc}^{3}$ & $34,6 \mathrm{bc}^{6}$ & $24,0 \mathrm{bc}^{7}$ & $829,8 \mathrm{bc}^{5}$ \\
\hline Elisa (AS) & $35,2 \mathrm{ab}^{7}$ & $20,4 \mathrm{~cd}^{6}$ & $583,4 \mathrm{e}^{15}$ & $33,2 \mathrm{bc}^{10}$ & $24,3 \mathrm{bc}^{5}$ & $810,9 \mathrm{bc}^{7}$ \\
\hline Média & $\mathbf{3 4 , 0 7}$ & 20,53 & 706,43 & 33,94 & 24,02 & 825,26 \\
\hline
\end{tabular}

* Números ao lado das letras minúsculas demonstram a ordem crescente das médias; valores seguidos de mesma letra na vertical não diferem entre si no teste Tukey (P<0,05);

** AR-altamente resistente, R-resistente, MR-moderadamente resistente, MS-moderadamente suscetível, AS-altamente suscetível. Genótipos negritos correspondem aos genótipos avaliados inicialmente (testemunhas).

Maiores números e freqüências de estômatos nas faces abaxial e adaxial foram associados a grupos de genótipos altamente suscetíveis (Tabela 2). Resultados similares foram observados nos patossistemas Lycopersicon spp.-Xanthomonas campestris pv. vesicatoria (14), amendoim-Phaeoisariopsis personata (18) e triticale-Tilletia indica (7).

Foi encontrada diferença significativa $(\mathrm{P} \sim 0,05)$ ao realizar $\mathrm{o}$ contraste ortogonal nas duas faces foliares, para os genótipos resistentes- $\mathrm{R}$ (AR, R e MR) e suscetíveis-S (MS e AS) para as variáveis número de estômatos (valor $\mathrm{F}=4,76 ; \mathrm{R}_{\text {médi a }}=130,0$ b e $\mathrm{S}_{\text {média }}=146,6$ a) e frequiência de estômatos (valor $F=9,76 ; R_{\text {média }}=19,3$ b e $S_{\text {média }}=$ 22,0 a) (Tabela 3).

Apesar de significativas, as diferenças encontradas no comprimento, largura e dimensão de estômatos, estes não se relacionaram com a classe de resistência de 15 genótipos de Capsicum (Tabela 4). Isso indica que outros mecanismos de resistência devem estar sobrepostos ao número de estômatos para determinação do grupo de resistência ao qual o genótipo pertence.

O número e frequiência de estômatos apresentados pelos genótipos são controlados geneticamente, e tem papel parcial na resistência a oídio em Capsicum. Além destas variáveis, existem fatores abióticos, como o déficit hídrico, que são os responsáveis pelo aumento e freqüência de estômatos nos vegetais (16).

O genótipo altamente suscetível ('Magali') e o altamente resistente ('HV-12') comportaram-se como bons marcadores da relação entre a estrutura estomatal e a reação ao oídio, exibindo o maior e o menor número e freqüência de estômatos, respectivamente (Tabelas 2 e 3 ). Para estes genótipos a resistência ao oídio é relacionada por fatores pré-infeccionais do hospedeiro, sem prejuízo de outros mecanismos de defesa. Entretanto, mais estudos são necessários, com maior número de genótipos, levando em consideração que também existem outros mecanismos, com maior efeito que os de defesa estruturais pré- formados, para estabelecimento da reação de resistência.

\section{AGRADECIMENTOS}

A Dra. Lucimara Blumer pelo auxílio na revisão estatística. A Profa. Marisa A.S.V. Ferreira, que quando ao ministrar a disciplina de Fisiopatologia Vegetal na UnB, despertou o interesse do primeiro autor em desenvolver um projeto relacionado a área. E pelo auxílio técnico nas atividades de Anatomia Vegetal de Ieda Nunes Cornélio. C.A. Lopes e A.C. Café Filho agradecem as bolsas de produtividade em pesquisa do $\mathrm{CNPq}$.

\section{REFERÊNCIAS BIBLIOGRÁFICAS}

1. Acuña, R.S.; Acuña, A.S.; Zambolim, L. Índice estomático en materiales genéticos de café resistentes o susceptibles a la roya. Bioagro, Viçosa, v.10, n.2, p.57-61, 1998.

2. Ahmad, K.J. Cuticular studies in Solanaceae. Canadian Journal of Botany, Ottawa, v.42, p.793-803, 1964.

3. Bergamin Filho, A. Curvas de progresso da doença. In: Bergamin Filho, A.; Kimati, H.; Amorim, L. (Ed.) Manual de fitopatologia: princípios e conceitos. 3 ed. Agronômica Ceres: São Paulo, 1995. p. 602-626.

4. Café Filho, A.C.; Coelho, M.V.S.; Souza, V.L. Oídios em hortaliças In: Stadnik, M.J.; Rivera, M.C. (Ed.) Oídios. Jaguariúna: Embrapa Meio Ambiente, 2001. p. 285-302.

5. Cutter, E. Anatomia vegetal. Parte 1 - Células e tecidos. São Paulo:Roca, 1987. 304 p.

6. Fukuda, C. Bacteriose da mandioca (Xanthomonas campestris pv. manihotis): resistência varietal e alguns possíveis fatores pré-infeccionais de resistência do hospedeiro. 1982. 58 p. Dissertação (Mestrado) - Universidade Federal de Viçosa, Viçosa.

7. Grewal, T.S.; Indu, S.; Aujla, S.S.; Sharma, I. Role of stomata and 
hairs in resistance/susceptibility of wheat to karnal bunt. Journal of Mycology and Plant Pathology, Bangalore, v. 29, n.2, p.217-221, 1999.

8. Iwaro, A.D.; Sreenivasan, T.N.; Umaharan, P. Phytophthora resistance in cacao (Theobroma cacao) influence of pod morphological characteristics. Plant Pathology, Oxford, v.46, n.4, p.557-565, 1997.

9. Lima, M.L.P.; Cornelio, I.N.; Café Filho, A.C. Correlação de variáveis do complexo estomático de pimentas e pimentões com grupos de resistência à Leveillula taurica (Lèv.) Arn. In: Congresso Nacional de Botânica, 2001, Paraíba. Anais. 2001. p. 62.

10. Lima, M.L.P.; Cornelio, I.N.; Café Filho, A.C. Correlação do progresso temporal de oídio com grupos de resistência e número de estômatos em Capsicum. Fitopatologia Brasileira, Fortaleza, v. 26 (suplemento) p. 443. 2001.

11. Palti, J. The Leveillula mildews. Botanical Review, Bronx, v.54, p. 423-535. 1988

12. Paz Lima, M.L.; Lopes, C.A.; Café Filho, A.C. Estabilidade da resistência de Capsicum spp. ao oídio em telado e casa de vegetação. Fitopatologia Brasileira, Fortaleza, v. 29, p.519-525, 2004.

13. Prabhpreet, I.; Dhillon, M.; Singh, P.P.; Inder, P. Pre-penetrati- on anatomical barriers of muskmelon leaf against downy mildew disease. Plant Disease Research, Ludhiana, v.14, n.1, p.1-6. 1999.

14. Ramos, L.J.; Narayanan, K.R.; McMillan JR., R.T. Association of stomatal frequency and morphology in Lycopersicon species with resistance to Xanthomonas campestris pv. vesicatoria. Plant Pathology, Oxford, v. 41, n.2, p.157-164, 1992.

15. Silva, H.; Martinez, J.P.; Baginsky, C.; Pinto, M. Effect of water stress on the leaf anatomy of six cultivars of the common bean Phaseolus vulgaris. Revista Chilena de Historia Natural. Santiago, v. 72, n.2, p.219-235, 1999.

16. Singh, D.N.; Singh, N.K.; Srivaska, S. Biochemical and morphological characters in relation to Alternaria blight resistance in rape seed-mustard. Annals of Agricultural Research, New Delhi, v.20, n.4, p.472-477, 1999.

17. Souza, V.L.; Café-Filho, A.C. Genetic resistance to Leveillula taurica in the genus Capsicum. Plant Pathology, Oxford, v. 52, p. 613-619, 2003.

18. Suryawanshi, A.P.; Mayee, C.D.; Apet, K.T. Static structural defence mechanisms against late leaf spot in groundnut. Journal of Maharashtra Agricultural Universities, Pune, v.19, n.1, p. $78-80.1994$ 